\title{
Mindfulness meditation and curiosity: The contributing factors to wellbeing and the process of closing the self-discrepancy gap
}

\author{
Itai Ivtzan · Hannah E. Gardner · Zhanar Smailova
}

\begin{abstract}
Actual/ideal self-discrepancy is the measurable difference between an individual's beliefs about who they think they are (actual self) and their image of the person they would ideally like to be (ideal self). When the self-discrepancy gap is small, higher psychological wellbeing exists. Mindfulness meditation, by means of greater awareness of the continuous fluctuation of thought from one point to another, has been shown to increase self-acceptance, which can lead to minimizing self-discrepancy. Additionally, curiosity is an important third factor in motivating the change required to reduce self-discrepancy. This study hypothesises that mindfulness meditation reduces actual-ideal self-discrepancy. Additionally, it hypothesises that higher trait curiosity will lead to a larger reduction in self-discrepancy. One hundred and twenty participants took part in a mindfulness meditation course. Before and after this, participants completed a Selves questionnaire and the Curiosity and Exploration Inventory. The findings confirm that mindfulness meditation can effectively reduce the gap between actual/ideal self attributes. In addition, curiosity is an influencing factor in making the largest changes in selfdiscrepancy after meditation.
\end{abstract}

Keywords: Mindfulness meditation, Curiosity, Actual-self, Ideal-self, Self-discrepancy, Positive Psychology

\section{Introduction}

\subsection{Self-concept}

Self-concept is an innate drive to define ourselves based on our evaluation of how our behaviour compares with the behaviour of others, and the judgments of others about our own behaviour (Sebastian, Burnett, \& Blakemore, 2008). Self-concept is our self-identity, a schema consisting of an organised collection of beliefs and feelings. In other words, self-concept provides a framework that determines how we process information about ourselves, including our motives, emotional states, self-evaluations, and abilities (Back, Schmukle, \& Egloff, 2009).

Self-concept is dynamic, as it responds to time alterations, challenges in the environment, and proactively motivates an individual towards change (Gordon \& Gergen, 1968; Markus \& Wurf, 1987). Markus and Nurius (1986) suggested that at any given time a self-concept is open to change in response to new experiences. In order to change our self-concept, various selfrepresentations exist which can serve as incentives or deterrents for our future behaviour (Markus \& Nurius, 1986). Self Discrepancy Theory (SDT; Higgins, 1987) describes three selfconceptions: one that represents the 'actual' self, which is the representation of the attributes an individual possesses, and is often what is meant by self-concept (e.g., Erikson, 1963; Lynch, La 
Guardia, \& Ryan, 2009; McDaniel \& Grice, 2007); one that represents an 'ideal' self, or the attributes an individual would ideally possess; and one that represents an 'ought' self, or characteristics the individual feels they should possess as their duty or obligation (Radu \& Loué, 2008; Higgins, 1989).

A discrepancy can exist between any two self-concepts. If a person possesses an actual versus ideal discrepancy, their current state of attributes does not match their ideal state. When we believe a negative event will occur, anxiety is felt; if we believe a positive event will never occur, depressive affect is felt (Higgins, Bond, Klein, \& Strauman, 1986; Woodman \& Hemmings, 2008; Scott \& O'Hara, 1993). Longitudinal studies have found that an actual/ideal discrepancy is associated with later depressive symptoms, as the positive ideal leads to disappointment; actual/ought discrepancy is associated with social anxiety, as responsibilities can lead to worry over future events going wrong (Strauman \& Higgins, 1988). Various other researchers have also found evidence that a felt discrepancy between the actual self and what one hopes to be can lead to disappointment and dissatisfaction (e.g., Boldero \& Francis, 2000; Bruch, Rivet, \& Laurenti, 2000; Fairbrother \& Moretti, 1998). Furthermore, accessibility to this discrepancy, through focusing on a potential or real negative event, can lead to heightened negative emotions (Scheier \& Carver, 1977; Higgins, Bond, Klein, \& Strauman, 1986). Therefore, given the psychological distress caused by a discrepancy of the actual and ideal self, an individual is motivated to reduce the gap between their ideal and actual self.

\subsection{Meditation as a way of minimising self-discrepancy}

Self-discrepancy occurs from false expectations - a prospect of something good which fails to happen - or the prospect of something threatening happening. Meditation can be used to reduce the self-discrepancy gap. This is because meditation techniques aim to focus attention in a non-analytical way and attempt not to dwell on discursive, ruminating thought (Moore \& Malinowski, 2009; Shapiro, 1982).

The present study uses mindfulness meditation, which involves individuals directly participating in each moment as it occurs with as much awareness as possible (Ivtzan, 2008; Zeidan, Johnson, Diamond, David, \& Goolkasian, 2010). Mindfulness meditation is more specifically called "insight meditation" in Buddhist traditions, or vipassanna, which in Sanskrit means "to see clearly." "Mindfulness" refers to orienting one's self to the present moment. Definitions commonly emphasize maintaining an awareness of one's immediate experience, as opposed to being distracted by the past or future, or being engaged in avoidance of one's experience. Mindfulness meditation is a formal discipline that attempts to create greater awareness and therefore foster greater insight in the practitioner. To support these definitions, Teasdale and his colleagues (2002) offer a model of mindfulness meditation which allows the practitioner to engage with and interrupt negative thinking (that otherwise might contribute to psychological distress) in a healthy way. La Toree (2003) discusses the benefits of mindfulness meditation in relation to the emotional benefits of self growth. Her explanation is based on the idea that overwhelming emotions are better able to be accepted and processed because an individual is able to accept and own these feelings and experience them with a sense of safety provided by the experience.

Hundreds of empirical studies have been carried out on the range of effects of meditation (e.g. Jain et al, 2007; Murphy, Donovan, \& Taylor, 1999). The practice of meditation has been used in psychotherapy, for promoting general wellbeing, as well as for the treatment of anxiety, addictions and pain management (Marlatt \& Kristeller, 1999; Rubin, 1996; Kabat-Zinn et al., 
1992). The link which explains the reasons behind the positive effects of meditation on wellbeing, however, is largely unexplored.

\subsection{Meditation and the self-concept}

One important benefit of meditation is the improvement of the self-concept and of selfacceptance (Jimenez, Niles, \& Park, 2010; Turnbull \& Norris, 1982). This is underlined in a study by Easterlin and Cardena (1998) which reveals that more experienced 'meditators' were more likely to report a higher sense of "acceptance" towards their self-concept when under stress. In a study by Turnbull and Norris (1982) data were collected from participants before and after starting the regular practice of TM (Transcendental Meditation). Results indicated that meditators began to perceive their actual selves as increasingly similar to their ideal and social selves (as they are envisaged by others), and that they developed a more strongly defined concept of their actual selves that involved increased self-acceptance.

Although mindfulness meditation is reported as having a powerful impact on the participant's attitude towards himself and others (e.g., Kabat-Zinn, 1990) only a few studies have dealt with its influence on the self-concept (Crane et al., 2008). As discussed by Crane et al. (2008), there are two other links between mindfulness meditation and self-discrepancy. The first is that instead of trying to change and experience conflict through cognitive processing, mindfulness meditation invites practitioners to observe their thoughts in an open, accepting, and non-judgmental way. By doing this, mindfulness meditation protects the practitioner against over-engagement with their potential self-discrepancy and therefore reduces the accessibility of self-discrepancy in challenging experiences. The second is that practitioners focus on self-acceptance and self-kindness whilst removing the need to change. This attitude encourages them to re-evaluate problematic or perfectionist goals thus reducing levels of selfdiscrepancy. Over time, the practice of mindfulness increases dispositional openness, through receptivity and curiosity (Costa \& McCrae, 1987).

\subsection{Trait curiosity - leading to personal growth}

Mindfulness is characterised by what is often referred to as 'beginners mind'; being aware and interested in seemingly mundane and established environments. It is unsurprising, therefore, that both everyday mindfulness and mindfulness meditation practice are highly correlated to the personality trait openness to experience (Baer, Smith, Hopkins, Krietemeyer, \& Toney, 2006; Ivtzan \& Conneely, 2009; Lau et al., 2006; Brown \& Ryan, 2003; Thompson \& Waltz, 2007), which is strongly associated with trait curiosity (Kashdan \& Steger, 2007). Trait curiosity involves recognition, pursuit, and intense desire to investigate novel, challenging, or puzzling phenomena (Kashdan, Rose, \& Fincham, 2004; Izard, 1977). Two factors encapsulate the trait: exploration and absorption (Kashdan, Rose \& Fincham, 2004). By intentionally seeking new and challenging experiences, individuals can stretch or expand their knowledge, skills, and goal-directed efforts (e.g., Ainley, Hidi, \& Berndorff, 2002; Fredrickson, 1998). Additionally, curious people are able to engage for prolonged periods because the search for knowledge is in itself enjoyable (Kashdan \& Steger, 2007), as are the thoughts about what remains to be discovered (Bryant \& Veroff, 2007; Wilson, Centerbar, Kermer, \& Gilbert, 2005).

Because of these characteristics, curiosity is linked to greater wellbeing in a number of different ways (e.g., Naylor, 1981; Park, Peterson, \& Seligman, 2004). Firstly, physical health is associated with curiosity, with those who are more curious aged $60-86$ being more likely to be alive after five years, even after accounting for age, smoker status, and various diseases (Swan \& Carmelli, 1996). Secondly, curious people report more satisfying social interactions and 
relationships, and their partners describe them as interested and responsive (Burpee \& Langer, 2005; Kashdan \& Roberts, 2004). Less curious people often rely on stereotypes, and avoid uncertainty by rejecting those who fail to conform (Sorrentino, Holmes, Hanna, \& Sharp, 1995). Finally, of the 24 VIA character strengths, curiosity was one of the most strongly linked to global life satisfaction, work satisfaction, living a pleasurable life, living an engaging life, and living a meaningful life (Brdar \& Kashdan, 2009; Park, Peterson, \& Seligman, 2004; Shimai, Otake, Park, Peterson, \& Seligman, 2006). A higher propensity to seek out novel and challenging events leads to participation in growth-oriented behaviours such as meditation, from which meaning in life, personal growth and wellbeing derive.

Trait curiosity is important in relation to this study in two ways. Firstly, it may be directly related to attempting to practice meditation, and being open to the positive changing effects of meditation. Secondly, curiosity may be directly linked to a reducing self-discrepancy. This is because minimising a self-discrepancy gap requires motivation to alter one's thought processes and/or behaviour. Curiosity is a personality trait which is highly correlated with intrinsic motivation to cognate (Cacioppo, Petty, Feinstein, Jarvis, \& Blair, 1996), and motivation altering behaviours (Reiss, 2004).

\subsection{The present study}

Despite promising findings on the effects of mindfulness meditation on wellbeing (Carboy \& Baer, 2008; Hjelle, 1974), further research is required to test the effectiveness of a mindfulnessbased intervention on self-discrepancy reduction. The current study expanded upon previous research by examining the potential benefits of a curiosity trait to cultivate mindfulness, a link not previously addressed. The first hypothesis was that mindfulness meditation would reduce a self-discrepancy gap between an actual and ideal self, because it encourages a nonjudgemental acceptance of the self. The second hypothesis was that the higher the individual's trait curiosity, the more helpful the mindfulness meditation would be, as shown in a larger reduction in the self-discrepancy gap. This is because curiosity motivates an individual to change behaviour, and increases openness to the positive effects of meditation.

\section{Method}

\subsection{Participants}

The sample consisted of 120 meditators attending a meditation workshop weekend in the "Osho Leela" meditation centre in Gillingham, UK. Of the 120 participants, 73\% were female and $27 \%$ were male. Participant ages ranged from 16 -to-61 years $(M=36, S D=15)$.

\subsection{Measures}

Participants provided relevant demographics and completed the following measures to assess curiosity levels and their self-discrepancy score:

Curiosity and Exploration Inventory (CEI; Kashdan, Rose, \& Fincham, 2004). The CEI is a selfreporting instrument which assesses individual differences in the recognition and pursuit of novel and challenging experiences. It uses a seven-item Likert-type scale with two factors. The first is exploration, which refers to striving for novel and challenging experiences (e.g., "I would describe myself as someone who actively seeks as much information as I can in a new situation"). The second is absorption, which refers to the tendency to deeply engage in activities (e.g., "When I am participating in an activity, I tend to get so involved that I lose track of time"). 
Selves questionnaire (Higgins, Klein, \& Strauman, 1985). The Selves questionnaire was used to measure participants' level of self-discrepancy between actual and ideal selves. Participants generated lists of up to 10 adjectives for each domain of the self: a) Actual self, "Your belief of the attributes and characteristics you currently possess" and b) Ideal self, "Your beliefs of attributes and characteristics you would ideally like to possess: that is the type of person you desire to be". Participants were asked to generate the lists from their own standpoints. A twostage process (Higgins, 1987) was used to quantify the discrepancy between the actual selfconcept and the ideal self-guide. The first stage involved a comparison of attributes in the actual self-concept to the attributes in the ideal self-guide using Webster's New World Thesaurus (Laird, 2002). Four types of attribute-pair relationships were calculated: (1) synonymous attributes that were found in the list of synonyms associated with the word, and were given a two-point weighting to the participant's score, were classed as matches; (2) attributes that were not found in the list of synonyms in the dictionary but were associated with one of the words in the list were classed as mismatches of extent. These attributes were given a one-point weighting. (3) Attributes that were antonyms were classed as mismatches; (4) attribute comparisons that yielded neither synonyms nor antonyms were considered nonmatches. Nonmatches were not included in the calculation of self-discrepancy scores. In the next stage the magnitude of discrepancy was quantified. Discrepancy scores were calculated by subtracting the total number of matches from the total number of mismatches, with true mismatches (attributes that were found in the list of antonyms in the dictionary) weighted twice as much as synonymous mismatches (attributes that were not found in the list of antonyms in the dictionary but were associated with one of the words in the list) and matches.

\subsection{Procedure}

The meditation workshop emphasised the need for spiritual development and used a variety of exercises as a way of experiencing mindfulness meditation. The workshop was intensive and lasted three days, throughout which participants learned mindfulness meditation in different environmental settings (e.g. walking outside in the garden or sitting still with eyes closed in a room).

At the beginning of the workshop, participants were briefed and asked to fill in the two questionnaires. They completed the Curiosity and Exploration Inventory (Kashdan, Rose, \& Fincham, 2004) and then filled in the Selves questionnaire (Higgins, Klein, \& Strauman, 1985). At the end of the workshop they were asked to fill in the Selves Questionnaire again in order to measure their level of self-concept after the course.

\section{Results}

A two-stage process (Higgins, 1987) was used to quantify the discrepancy between the actual self-concept and the ideal self-guide for each participant before and after meditation, as shown in Figure 1 (below). 


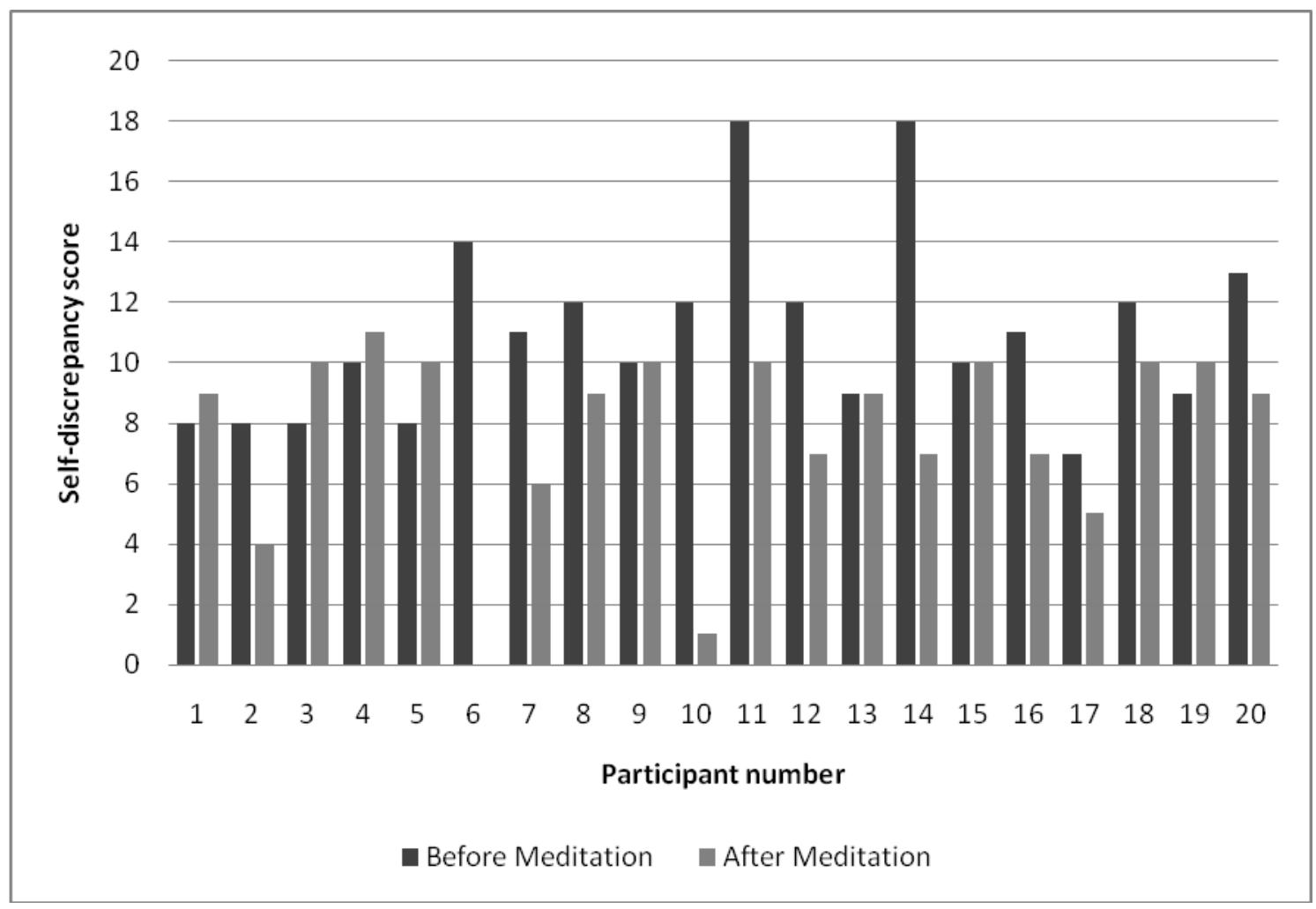

Figure 1: Discrepancy scores for the first 20 participants before and after meditation

Table 1 shows that self-discrepancy mean scores after meditation $(M=7.70)$ decreased in comparison with scores before the intervention $(M=11.00)$.

Table 1: Means, standard deviations and range of the discrepancy scores pre- and postmeditation

\begin{tabular}{lrrrrr}
\hline & $\mathrm{N}$ & \multicolumn{2}{c}{ Range } & Mean & SD \\
\hline & & Minimum & Maximum & \\
\hline Pre-meditation & 120 & 7.00 & 18.00 & 11.00 & 3.06 \\
\hline Post-meditation & 120 & .00 & 11.00 & 7.70 & 3.11 \\
\hline
\end{tabular}

The first hypothesis was that there would be a decrease in real-ideal discrepancy as a result of Meditation practice. To test the difference in self-discrepancies pre- and post-meditation, a paired samples t-test was computed. The difference between scores pre- $(M=11.00, S D=3.06)$ and post-meditation $(M=7.70, S D=3.11)$ was statistically significant: $t(19)=3.18, p<.005$.

Curiosity scores, using the Curiosity and Exploration Inventory (CEI), were calculated for each participant. CEI results indicated a higher than average level of curiosity in all participants $(M=5.09 ; S D=0.72)$. To test the assumption of the second hypothesis, Pearson Product Moment correlation coefficients were computed between CEI scores and change in self- 
discrepancy scores. There was a statistically significant relationship $(r=.69, p<.001)$ showing that a reduction in self-discrepancy scores is associated with a higher curiosity level. ${ }^{1}$

\section{Discussion}

\subsection{Review of findings}

This study aimed to analyse the association between meditation and a reduction in a discrepancy between 'actual' and 'ideal' selves. Additionally, it aimed to explore the process by which meditation is most effective, by analysing the effect of a third variable in this process; trait curiosity. The first hypothesis was that there would be a decrease in real-ideal discrepancy as a result of mindfulness meditation practice. The study found that the practice of meditation had a salutary influence on a subject's psychological state as measured by the Selves questionnaire. An analysis of the profiles showed that after meditation the gap between participants ideal and actual selves reduced compared to before meditation. Therefore, participants practising mindfulness meditation moved towards a psychological state to which they were aspiring when learning the technique.

Another purpose of the study was to test whether the changing scores in the actual-ideal discrepancies are positively correlated with levels of trait curiosity. The results reveal that the correlation was significant, suggesting that there is a relationship between curiosity and the psychological process of closing the gap between their actual-ideal self-concepts. In addition, a higher than average level of curiosity in all participants may suggest that people who are attracted to meditation and events that encourage personal growth and meaning in life, in general, are initially more curious than those who are not. Thus, the results suggest that trait curiosity predicts wellbeing by leading to minimising the level of discrepancy between the actual and ideal selves.

The results of this study indicate that mindfulness meditation leads to a psychological transformation from which participants feel more comfortable with themselves (Lykins \& Baer, 2009). Furthermore, meditating individuals might become accepting towards their self-concept and their self-representations, and as they experience relative peace, their vulnerability to dejection-related emotions reduces (Woodman \& Hemmings, 2008; Scott \& O'Hara, 1993). In a study by Shapiro, Schwartz, and Bonner (1998), Mindfulness Based Stress Reduction (MBSR) was offered to medical and pre-medical students. This study included reduced self-reports of overall psychological distress including depression, reduced self-reports of anxiety and increased scores of empathy levels. The current study suggests that this process may at least partly depend on a decrease in self-discrepancy. The current study, therefore, encourages the understanding of mindfulness meditation as an important intervention tool leading to psychological wellbeing. Any health practitioner might benefit from understanding mindfulness meditation as a potential intervention which might allow clients and patients a more coherent sense of self which is accompanied with a deeper feeling of acceptance.

The findings that curiosity is (1) an important factor in how successful mindfulness meditation is in reducing self-discrepancy, and (2) higher in the meditators overall, suggests that curiosity is crucial to providing a sense of life direction and purpose. Findings are also in line with Tomkins' (1962) conclusion that curiosity has a distinct function of motivating the exploration of the self and the world, and thus expanding knowledge and skills. Finally, the

\footnotetext{
${ }^{1}$ It should be noted that the veracity of this surprisingly strong result has been questioned since the publication of this article. The authors maintain that the result is legitimate, but they were unable to obtain the original data that could have verified this result.
} 
results of this investigation are consistent with the behavioural congruence model (Côté \& Moskowitz, 1998), which states that people high in trait curiosity tend to extract greater meaning and satisfaction from life.

The present research focused on the consequences of mindfulness meditation for wellbeing, but future research could explore a number of related avenues. Firstly, a longitudinal study would allow the discovery of whether meditation can alter trait curiosity. Assessing individuals over a significant time would additionally analyse long-term benefits of mindfulness training on self-discrepancy. Secondly, personality traits such as neuroticism may negatively impact on the effect of meditation. Finally, we are as yet unclear about the positive effect of personality traits paired with meditation on other factors which influence wellbeing and self- and other-acceptance. Therefore, extended research beyond this paper would greatly develop our limited understanding of the interplay of mindfulness meditation and personality on wellbeing.

This study advocates that mindfulness meditation can effectively reduce the gap between actual and ideal self attributes, leading to potential greater wellbeing. In addition, curiosity may act as a tool for searching and obtaining engagement with personally meaningful activities which might be beneficial to wellbeing. Both internal factors (e.g. curiosity) and external factors (e.g. accessibility of meditation) interplay to produce higher psychological wellbeing.

\section{Authors}

Itai Ivtzan

University College London

ItaiIvtzan@AwarenessIsFreedom.com

Hannah E. Gardner

University College London

h.gardner@psych.york.ac.uk

Zhanar Smailova

University College London

z.smailova@ucl.ac.uk

\section{Publishing Timeline}

Received 30 July 2011

Accepted 25 September 2011

Published 25 October 2011

Updated 14 February 2013

\section{References}

Ainley, M., Hidi, S., \& Berndorff, D. (2002). Interest, learning and the psychological processes that mediate their relationship. Journal of Educational Psychology, 94, 545-561.

http://dx.doi.org/10.1037/0022-0663.94.3.545

Back, M. D., Schmukle, S. C., \& Egloff, B. (2009). Predicting actual behavior from the explicit and implicit self-concept of personality. Journal of Personality and Social Psychology, 97, 533-548.

http://dx.doi.org/10.1037/a0016229

Baer, R. A., Smith, G. T., Hopkins, J., Krietemeyer, J., \& Toney, L. (2006). Using self-report assessment methods to explore facets of mindfulness. Assessment, 1, 27-45.

http://dx.doi.org/10.1177/1073191105283504 
Boldero, J., \& Francis, J. (2000). The relation between self discrepancies and emotion: The moderating roles of self-guide importance, location relevance, and social self-domain centrality. Journal of Personality and Social Psychology, 78, 38-52. http://dx.doi.org/10.1037/0022-3514.78.1.38

Brdar, I., \& Kashdan, T. B. (2009). Strengths and well-being in Croatia. Unpublished raw data.

Brown, K. W., \& Ryan, R. M. (2003). The benefits of being present: Mindfulness and its role in psychological wellbeing. Journal of Personality and Social Psychology, 84, 822-848. http://dx.doi.org/10.1037/0022-3514.84.4.822

Bruch, M. A., Rivet, K. M., \& Laurenti, H. J. (2000). Type of self-discrepancy and relationships to components of the tripartite model of emotional distress. Personality and Individual Differences, 29, 3744. http://dx.doi.org/10.1016/S0191-8869(99)00176-2

Bryant, F. B., \& Veroff, J. (2007). Savoring: A new model of positive experience. Mahwah, NJ: Erlbaum.

Burpee, L. C., \& Langer, E. J. (2005). Mindfulness and marital satisfaction. Journal of Adult Development, 12, 43-51. http://dx.doi.org/10.1007/s10804-005-1281-6

Cacioppo, J. T., Petty, R. E., Feinstein, J. A., Jarvis, W., \& Blair, G. (1996). Dispositional differences in cognitive motivation: The life and times of individuals varying in need for cognition. Psychological Bulletin, 119, 197-253. http://dx.doi.org/10.1037/0033-2909.119.2.197

Carmody, J., \& Baer, R. A. (2008). Relationships between mindfulness practice and levels of mindfulness, medical and psychological symptoms and well-being in a mindfulness-based stress reduction program. Journal of Behavioral Medicine 31, 23-33.

Costa, P. T., \& McCrae, R. R. (1987). Personality assessment in psychosomatic medicine: Value of trait taxonomy. In G. A. Fava and T. N. Wise (Eds.), Advances in psychosomatic medicine: Research paradigms in psychosomatic medicine (pp.71-82). Basel, Switzerland: Karger.

Côté, S., \& Moskowitz, D. S. (1998). On the dynamic covariation between interpersonal behaviour and affect: Prediction from neuroticism, extraversion, and agreeableness. Journal of Personality and Social Psychology, 75, 1032-1046. http://dx.doi.org/10.1037/0022-3514.75.4.1032

Crane, C., Barnhofer, T., Duggan, D., Hepburn, S., Fennell, M. J. V., \& Williams, J. M. G. (2008). Mindfulness-based cognitive therapy and self-discrepancy in recovered depressed patients with a history of depression and suicidality. Cognitive Therapy \& Research, 32, 775-787. http://dx.doi.org/10.1007/s10608-008-9193-y

Easterlin, B., \& Cardena, E. (1998). Cognitive and emotional differences between short- and long-term Vipassana meditators. Imagination, Cognition \& Personality, 18, 9-81.

Erickson, E. H. (1963). Childhood and society (2nd ed.). New York: Norton.

Fairbrother, N., \& Moretti, M. (1998). Sociotropy, autonomy, and self-discrepancy: Status in depressed, remitted depressed, and control participants. Cognitive Therapy and Research, 22, 279-296. http://dx.doi.org/10.1023/A:1018796810260

Fredrickson, B. L. (1998). What good are positive emotions? Review of General Psychology, 2, 300-319. http://dx.doi.org/10.1037/1089-2680.2.3.300

Gordon, C., \& Gergen, K. J. (1968). The self in social interaction: Volume 1. New York Wiley.

Higgins, E. T. (1987). Self-discrepancy: A theory relating self and affect. Psychological Review, 94, 319-340. http://dx.doi.org/10.1037/0033-295X.94.3.319

Higgins, E. T. (1989). Self-discrepancy theory: What patterns of self-beliefs cause people to suffer? In L. Berkowitz (Ed.), Advances in experimental social psychology, 2, pp. 93-136. New York: Academic Press.

Higgins, E. T., Bond, R. N., Klein, R., \& Strauman, T. (1986). Self-discrepancies and emotional vulnerability: How magnitude, accessibility, and type of discrepancy influence affect. Journal of Personality and Social Psychology, 51, 5-15. http://dx.doi.org/10.1037/0022-3514.51.1.5

Higgins, E. T., Klein, R., \& Strauman, T. (1985). Self-concept discrepancy theory: A psychological model for distinguishing among different aspects of depression and anxiety. Social Cognition, 3, 51-76. http://dx.doi.org/10.1521/soco.1985.3.1.51

Hjelle, L. A. (1974). Transcendental meditation and psychological health. Perceptual and Motor Skills, 39, 623-628. http://dx.doi.org/10.2466/pms.1974.39.1.623

Ivtzan, I. (2008). Meditation on consciousness. Journal of Scientific Exploration, 22(2), 147-160. 
Ivtzan, I., \& Conneely, R. (2009). Androgyny in the mirror of self-actualisation and spiritual health. The Open Psychology Journal, 2, 58-70.

Izard, C. E. (1977). Human emotions. New York: Plenum.

Jain, S., Shapiro, S. L., Swanick, S., Roesch, S. C., Mills, P. J., Bell, I., \& Schwartz, G. E. (2007). A randomized controlled trial of mindfulness meditation versus relaxation training: Effects on distress, positive states of mind, rumination, and distraction. Annals of Behavioral Medicine, 33(1), 11-21. http://dx.doi.org/10.1207/s15324796abm3301 2

Jimenez, S. S., Niles, B. L., \& Park, C. L. (2010). A mindfulness model of affect regulation and depressive symptoms: Positive emotions, mood regulation expectancies, and self-acceptance as regulatory mechanisms. Personality and Individual Differences, 49(6), 645-650. http://dx.doi.org/10.1016/j.paid.2010.05.041

Kabat-Zinn, J. (1990). Full catastrophe living: How to cope with stress, pain and illness using mindfulness meditation. New York: Dell Publishing.

Kabat-Zinn, J., Massion, A. O., Kristeller, J., Peterson, L. G., Fletcher, K, Pbert, L., Linderking, W., \& Santorelli, S. F. (1992). Effectiveness of a meditation-based stress reduction program in the treatment of anxiety disorders. American Journal of Psychiatry, 149, 936-943.

Kashdan, T. B., \& Roberts, J. E. (2004). Trait and state curiosity in the genesis of intimacy: Differentiation from related constructs. Journal of Social and Clinical Psychology, 23, 792-816. http://dx.doi.org/10.1521/jscp.23.6.792.54800

Kashdan, T. B., Rose, P., \& Fincham, F. D. (2004). Curiosity and exploration: Facilitating positive subjective experiences and personal growth opportunities. Journal of Personality Assessment, 82, 291305. http://dx.doi.org/10.1207/s15327752jpa8203 05

Kashdan, T. B., \& Steger, M. F. (2007). Curiosity and pathways to well-being and meaning in life: Traits, states and everyday behaviours. Motivation and Emotion, 31, 159-173. http://dx.doi.org/10.1007/s11031-007-9068-7

La Torre, M. A. (2003). A holistic view of psychotherapy: Connecting mind, body, and spirit. Perspectives in Psychiatric Care, 36(2), 67-68. http://dx.doi.org/10.1111/j.1744-6163.2000.tb00693.x

Laird, C. (2002). Webster's New World Dictionary and Thesaurus. London: John Wiley \& Sons.

Lau, M. A., Bishop, S. R., Segal, Z. V., Buis, T., Anderson, N. D., Carlson, L., \& Carmody, J. (2006). The Toronto Mindfulness Scale: development and validation. Journal of Clinical Psychology, 62(12), 14451467. http://dx.doi.org/10.1002/jclp.20326

Lykins, E. L. B., \& Baer, R. A. (2009). Psychological functioning in a sample of long-term practitioners of mindfulness meditation. Journal of Cognitive Psychotherapy, 23(3), 226-241. http://dx.doi.org/10.1891/0889-8391.23.3.226

Lynch, M. F., La Guardia, J. G., \& Ryan, R. M. (2009). On being yourself in different cultures: Ideal and actual self-concept, autonomy support, and wellbeing in China, Russia, and the United States. The Journal of Positive Psychology, 4(4), 290-304. http://dx.doi.org/10.1080/17439760902933765

Markus, H., \& Wurf, E. (1987). The dynamic self-concept: A social psychological perspective. Annual Review of Psychology, 38, 299-337. http://dx.doi.org/10.1146/annurev.ps.38.020187.001503

Markus, H., \& Nurius, P. (1986). Possible selves. American Psychologist, 41, 954-969. http://dx.doi.org/10.1037/0003-066X.41.9.954

Marlatt, G. A., \& Kristeller, J. L. (1999). Mindfulness and meditation. In W.R. Miller (Ed.), Integrating spirituality in treatment: Resources for practitioners, pp. 67-84. Washington, D.C.: American Psychological Association.

McDaniel, B. L., \& Grice, J. W. (2007). Predicting psychological wellbeing from self-discrepancies: A comparison of idiographic and nomothetic measures. Self and Identity, 7(3), 243-261. http://dx.doi.org/10.1080/15298860701438364

Moore, A., \& Malinowski, P. (2009). Meditation, mindfulness and cognitive flexibility. Consciousness and Cognition, 18(1), 176-186. http://dx.doi.org/10.1016/j.concog.2008.12.008

Murphy, M., Donovan, S., Taylor, E. (1999). The physical and psychological effects of meditation. Sausalito, CA: Institute of Noetic Science. 
Naylor, F. D. (1981). A state-trait curiosity inventory. Australian Psychologist, 16(2), 172-183. http://dx.doi.org/10.1080/00050068108255893

Park, N., Peterson, C., \& Seligman, M. E. P. (2004). Strengths of character and wellbeing. Journal of Social and Clinical Psychology, 23, 603-619. http://dx.doi.org/10.1521/jscp.23.5.603.50748

Radu, M., \& Loué, C. (2008). Motivational impact of role models as moderated by "ideal" vs. "ought selfguides" identifications. Journal of Enterprising Culture, 16(4), 441-465. http://dx.doi.org/10.1142/S0218495808000223

Reiss, S. (2004). Multifaceted nature of intrinsic motivation: The theory of 16 basic desires. Review of General Psychology, 8, 179-193. http://dx.doi.org/10.1037/1089-2680.8.3.179

Rubin, J. B. (1996). Psychotherapy and Buddhism: Toward an integration. Plenum Press. New York.

Scheier, M. F., \& Carver, C. S. (1977). Self-focused attention and the experience of emotion: Attraction, repulsion, elation and depression. Journal of Personality and Social Psychology, 35, 625-636. http://dx.doi.org/10.1037/0022-3514.35.9.625

Scott, L., \& O'Hara, M. W. (1993). Self-discrepancies in the clinically anxious and depressed university students. Journal of Abnormal Psychology, 102, 282-287. http://dx.doi.org/10.1037/0021-843X.102.2.282

Sebastian, C., Burnett, S., \& Blakemore, S. J. (2008). Development of the self-concept during adolescence. Trends in Cognitive Sciences, 12, 441-446. http://dx.doi.org/10.1016/j.tics.2008.07.008

Shapiro, D. H. (1982). Overview: Clinical and physiological comparisons of meditation with other selfcontrol strategies. American Journal of Psychiatry. 139, 267-274.

Shapiro, S. L., Schwartz, G. E., \& Bonner, G. (1998). Effects of mindfulness-based stress reduction on medical and premedical students. Journal of Behavioural Medicine, 21, 581-599. http://dx.doi.org/10.1023/A:1018700829825

Shimai, S., Otake, K., Park, N., Peterson, C., \& Seligman, M. E. P. (2006). Convergence of character strengths in American and Japanese young adults. Journal of Happiness Studies, 7, 311-322. http://dx.doi.org/10.1007/s10902-005-3647-7

Sorrentino, R. M., Holmes, J. G., Hanna, S. E., \& Sharp, A. (1995). Uncertainty orientation and trust in close relationships: Individual differences in cognitive styles. Journal of Personality and Social Psychology, 68, 314-327. http://dx.doi.org/10.1037/0022-3514.68.2.314

Strauman, T. J., \& Higgins, E. T. (1988). Self-discrepancies as predictors of vulnerability to distinct syndromes of chronic emotional distress. Journal of Personality, 56, 685-707. http://dx.doi.org/10.1111/j.1467-6494.1988.tb00472.x

Swan, G. E., \& Carmelli, D. (1996). Curiosity and mortality in aging adults: A 5-year follow-up of the Western Collaborative Group Study. Psychology and Aging, 11, 449-453. http://dx.doi.org/10.1037/0882-7974.11.3.449

Teasdale, J. D., Segal, Z. V., Williams, J. M. G., Ridgeway, V. A., Soulsby, J. M., Lau, M. A. (2002). Prevention of relapse in major depression by mindfulness-based cognitive therapy. Journal of Consulting Clinical Psychology, 68, 615-623. http://dx.doi.org/10.1037/0022-006X.68.4.615

Thompson, B. L., \& Waltz, J. (2007). Everyday mindfulness and mindfulness meditation: Overlapping constructs or not? Personality and Individual Differences, 43, 1875-1885. http://dx.doi.org/10.1016/j.paid.2007.06.017

Tomkins, S. S. (1962). Affect, imagery, consciousness: Vol. 1, The positive affects. New York: Springer.

Turnbull, M. J., \& Norris, H. (1982). Effects of transcendental meditation on self-identity indices and personality. British Journal of Psychology, 73, 57-68. http://dx.doi.org/10.1111/j.20448295.1982.tb01790.x

Wilson, T. D., Centerbar, D. B., Kermer, D. A., \& Gilbert, D. T. (2005). The pleasures of uncertainty: Prolonging positive moods in ways people do not anticipate. Journal of Personality and Social Psychology, 88, 5-21. http://dx.doi.org/10.1037/0022-3514.88.1.5

Woodman, T., \& Hemmings, S. (2008). Body image self-discrepancies and affect: Exploring the feared body self. Self and Identity, 7(4), 413-429. http://dx.doi.org/10.1080/15298860701800225 
Zeidan, F., Johnson, S. K., Diamond, B. J., David, Z., \& Goolkasian, P. (2010). Mindfulness meditation improves cognition: Evidence of brief mental training. Consciousness and Cognition, 19, 597-605. http://dx.doi.org/10.1016/j.concog.2010.03.014 